\title{
Population size, structure and habitat features of Haworthia koelmaniorum var. momurtryi, an endemic plant from Mpumalanga Province, South Africa
}

\author{
Authors: \\ Armand A. Biko'o ${ }^{1}$ \\ Dawid G.C. du Plessis \\ Willem J. Myburgh ${ }^{1}$ \\ Affiliations: \\ ${ }^{1}$ Department of Nature \\ Conservation, Tshwane \\ University of Technology, \\ South Africa \\ Correspondence to: \\ Armand Biko'o \\ Email: \\ bikooaa@tut.ac.za \\ Postal address: \\ Private Bag X680, Pretoria \\ 0001, South Africa \\ Dates: \\ Received: 24 Aug. 2010 \\ Accepted: 01 Apr. 2011 \\ Published: 07 July 2011 \\ How to cite this article: \\ Biko'o, A.A., Du Plessis, \\ D.G.C., Myburgh, W.J., 2011, \\ 'Population size, structure \\ and habitat features of \\ Haworthia koelmaniorum \\ var. momurtryi, an endemic \\ plant from Mpumalanga \\ Province, South Africa', \\ Koedoe 53(1), Art. \#1025, 8 \\ pages. doi:10.4102/koedoe. \\ v53i1.1025
}

C 2011. The Authors. Licensee: AOSIS OpenJournals. This work is licensed under the Creative Commons Attribution License.
Haworthia koelmaniorum Oberm. \& D.S. Hardy var. momurtryi (C.L. Scott) M.B. Bayer is an endemic plant restricted to the high-lying areas of Mpumalanga Province in South Africa. There is a serious lack of information on this species; it was known from only two populations at the time of the study but this information did not include population sizes and structures or its habitat requirements. A total count was conducted of one of the two populations to determine its size. Recorded plants were classified into age groups - according to their size and number of leaves - to determine the population structure. A detailed investigation of the habitat features of the studied population was also conducted. It was found that the studied population consisted of 1284 individuals and comprised approximately $4 \%$ seedlings, $12 \%$ juveniles and $84 \%$ mature plants. The species was found to have specialised habitat requirements, occurring only on red rhyolite of the Selons River Formation. The plants were also found to select very specific habitat features within their range of occurrence. The species also seems to be adapted to fire and has developed strategies to survive fire events. It is recommended that future research projects on this species use the same methods and age groups as this study to facilitate comparison. It is also recommended that more research be initiated to determine the population and seed viability, specific pollinators and the optimum fire frequency and intensity for this species.

Conservation implications: This article provides baseline information related to the size, structure and habitat features of one of two known populations of Haworthia koelmaniorum var. mcmurtryi. This information will contribute to the understanding of the ecology of this plant, thus contributing to better management decisions to enhance its in situ conservation.

\section{Introduction}

The extinction rate of species worldwide is increasing and threatens the biodiversity of nature (Baumgärtner et al. 2006; Pimm \& Raven 2000). The extinction of species represents a loss of biological diversity (Dobson 2000; Van Dyke 2003). The Convention on Biological Diversity, ratified by South Africa on 02 November 1995 (Secretariat of the Convention on Biological Diversity 2005), states that the broad objective of conservation is to conserve all types of biological diversity (United Nations 1992). Thus, conservation biology should focus efforts on the conservation of rare and endemic plants because they are more prone to extinction.

Haworthia koelmaniorum var. momurtryi is a rare and endemic plant species restricted to the Highveld area of Mpumalanga Province in South Africa. Its population size, population structure and habitat features have hitherto been unknown. H. koelmaniorum var. mcmurtryi was listed as being endemic to what was then known as the Transvaal region, with an indeterminate status both locally and globally (Hilton-Taylor 1996). In 1998, it was also listed in the Mpumalanga Nature Conservation Act (Act No. 10 of 1998; Mpumalanga Government) as vulnerable (Bosch 2004) and is therefore protected in the province. In 2009, it was listed as endangered (Lötter, Biko'o \& Victor 2009). It is important to know the population size and structure of this plant species, as well as its habitat requirements, as these data will allow for sound management practices to ensure that this species does not become extinct in the near future.

$H$. koelmaniorum belongs to the family Asphodelaceae. It comprises two varieties, namely $H$. koelmaniorum var. koelmaniorum and H. koelmaniorum var. momurtryi. The former is associated with sandy soil on quartzite whilst the latter is associated clayey soil on rhyolite. The morphological differences between the two varieties are summarised in Bosch (2004). H. koelmaniorum var. mcmurtryi (Figure 1) is a small succulent plant that can be described as a stemless rosette. It grows up to $15 \mathrm{~cm}$ in diameter. The leaves are $7 \mathrm{~cm}-10 \mathrm{~cm}$ long, dark brownish-green, opaque, and 
somewhat recurved. They have small raised tubercles and their margins and keel have small spines. The flowers are slender, creamy white, with petals fused and with revolute tips (Bayer 1999). In the dry season, the plant retracts almost completely underground with only the upper parts of some leaves visible above ground, making it very difficult to detect.

Rare and endemic plant taxa have many attributes that render them more vulnerable to extinction than others (Farnsworth et al. 2006; Van Dyke 2003). Human activity can modify the entire extent of their narrow geographic range, leading to their extinction. Rare species confined to only one or a few populations, such as H. koelmaniorum var. momurtryi, have a greater chance of becoming extinct (Van Dyke 2003) because the probability of all populations becoming extinct is higher, as a result of genetic and environmental stochasticity. Finally, species with specialised habitat requirements are threatened when human activity alters their environments (Primack 1993).

Small populations are more vulnerable to environmental and demographic variability, as well as to losses of genetic variability (Van Dyke 2003). The genetic makeup of a population determines its ability to adapt to changing conditions. Genetic drift and inbreeding are the two mechanisms operating in small populations that influence their genetic variation, whereby genetic variation is determined by the joint action of natural selection and genetic drift. In small populations the relative importance of genetic drift is higher; deleterious alleles can become more frequent and fixed in a population by chance, resulting in the loss of genetic variability. If such genetic diversity is lost, a species loses its ability to adapt to a changing environment (Holsinger 2000; Menges \& Dolan 1998; Van Dyke 2003).

Stochastic variations in demographic rates cause small populations to fluctuate randomly in size and the smaller the population, the greater the probability that fluctuations will lead to extinction. Small populations are subject to a higher chance of extinction because they are more vulnerable to genetic drift, resulting in stochastic variation in their gene pool, their demography and their environment (Van Dyke 2003). Stochastic variation in the environment can produce temporally correlated birth and death rates (i.e. good years when birth rates are high and death rates are low and bad years when birth rates are low and death rates are high) that lead to fluctuations in the population size. Smaller populations are therefore more likely to go extinct as a result of these environmentally generated population fluctuations than large populations because the population size can be reduced to such an extent during bad years that it never recovers again (Ellstrand \& Elam 1993).

A research project was conducted between 2004 and 2007 to bridge the knowledge gap on $H$. koelmaniorum var. momurtryi. The project specifically investigated the size and structure of the population and the habitat requirements of this plant species in its area of occurrence. This article summarises and discusses the results obtained in an attempt to allow for a

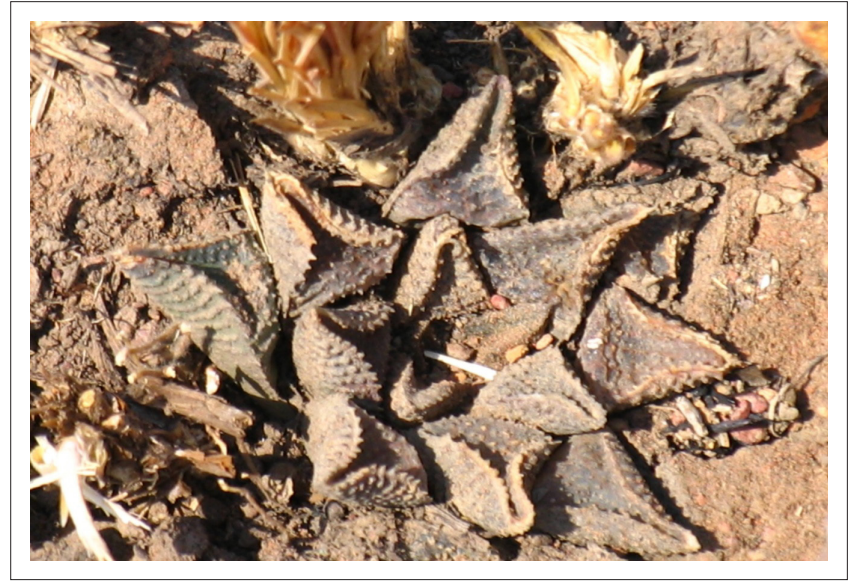

Source: Photo taken by Armand Biko'o

FIGURE 1: Mature Haworthia koelmaniorum var. Mcmurtryi, taken in September 2006 in the Dooringfontein population of the Loskop Dam Nature Reserve.

better understanding of the ecology of this plant. The paper also provides management recommendations for the in situ conservation of this species, thus contributing to its longterm survival.

\section{Methods \\ Study area}

The project was conducted at the Loskop Dam Nature Reserve (LDNR) and its surroundings. The reserve is situated approximately $55 \mathrm{~km}$ north of Middelburg in Mpumalanga Province, South Africa. The LDNR is situated in the upper catchment of the Olifants River system, between $25^{\circ} 22^{\prime} \mathrm{S}$ and $25^{\circ} 31^{\prime} \mathrm{S}$ and between $29^{\circ} 10^{\prime} \mathrm{E}$ and $29^{\circ} 24^{\prime} \mathrm{E}$ (Figure 2 ), and is underlain by six geological formations including the Rhyolite of the Selons River and Damwall Formations (Group Rooiberg) in which H. koelmaniorum var. momurtryi occurs. The reserve is located between the Moist Highveld Grassland (Region 11) and the Central Bushveld (Region 2) of the revised Köppen climatic classification (Kruger 2004). The mean long-term rainfall for the LDNR for the period ranging from 1961 to 2006 is $623 \mathrm{~mm}$ per annum. According to Mucina and Rutherford (2006), the LDNR consists of three vegetation types: the Central Sandy Bushveld (SVcb 12), the Loskop Mountain Bushveld (SVcb 13) and the Loskop Thornveld (SVcb 14). The study population was situated in the Loskop Mountain Bushveld, which occupies the low mountains and ridges with open tree savannah on lowerlying areas (Mucina \& Rutherford 2006).

\section{Design and procedure}

During the study period, the plant was known only from two populations, one in the Langkloof area and the other in the Dooringfontein area in and around the LDNR. The population at Langkloof is small with an estimated size of approximately 250 plants (A.C. Hoffman [Mpumalanga Tourism and Parks Agency] pers. comm., 12 October 2007). This population was discovered after the data collection period and was thus not included in this project. Only the population at Dooringfontein was studied for the purposes of this paper and is hereafter referred to as the population. 


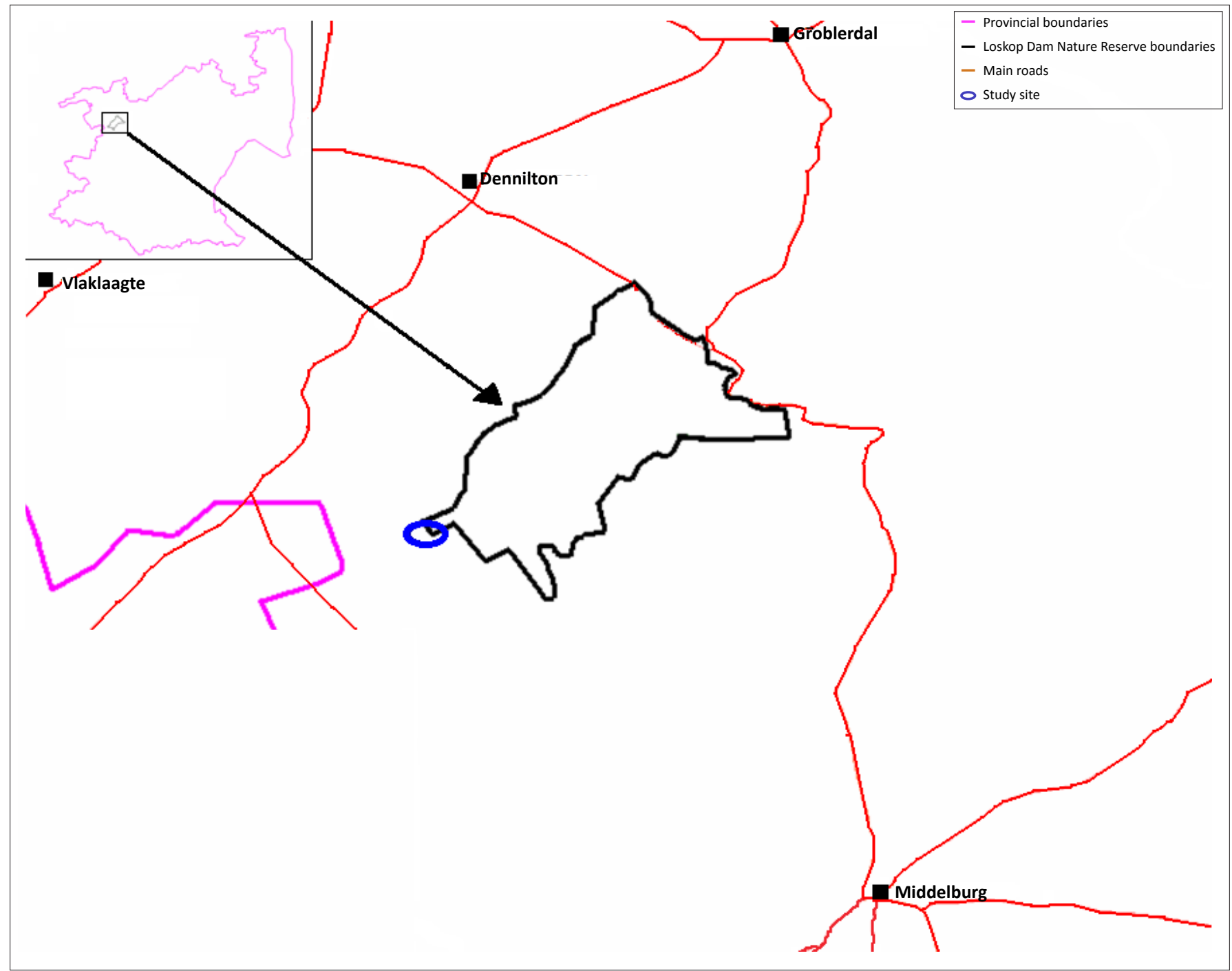

FIGURE 2: Location of the study site in Mpumalanga Province, South Africa.

The population consisted of four subpopulations that were subjectively called A, B, C and D. The field data were collected from the population over a four-year period (2004-2007) and during the same season annually (March-April for habitat features and August-September for population data).

\section{Population size and structure}

A total count was conducted. A number of transects, $2.5 \mathrm{~m}$ wide, were placed across the width of the subpopulations. Each transect was traversed by one person who systematically searched for H. koelmaniorum var. momurtryi plants. Each plant found was recorded and marked to prevent individual plants from being counted more than once. This method was adapted from Pfab and Witkowski (1999). The transects were laid out systematically to cover each subpopulation completely (Figure 3) and only one transect was counted at a time. The size of randomly selected individual plants was also measured in each subpopulation. In Subpopulations A, B, C and D, respectively, 78, 81, 81 and 82 individual plants were selected. The size was quantified as the average of the widest diameter of area covered by the plant $\left(D_{1}\right)$ and the diameter perpendicular to this $\left(D_{2}\right)$. This, together with the number of leaves, was used to classify the plants into age classes. Subjective classes based on observations were defined to classify every plant encountered as follows:

- Seedlings: Plants having one or two leaves, or having three leaves and an average diameter less than $20 \mathrm{~mm}$.

- Juvenile plants: Plants showing either primary or secondary growth characteristics, but with no evidence of flower formation. More precisely, these were plants with three leaves and an average diameter larger than or equal to $20 \mathrm{~mm}$, or plants having four or five leaves, no evidence of flower production, and a diameter less than or equal to $30 \mathrm{~mm}$.

- Sexually mature plants: Plants showing true flower formation or positively identifiable signs of flower formation. These were plants with five leaves or more and with a diameter larger than $30 \mathrm{~mm}$, or with evident signs of flower formation.

- Senescent plants: Post-reproductive plants. It was impossible to use this category with the Haworthia plants as it is very difficult to identify the post-reproductive size and/or age for these plants. 


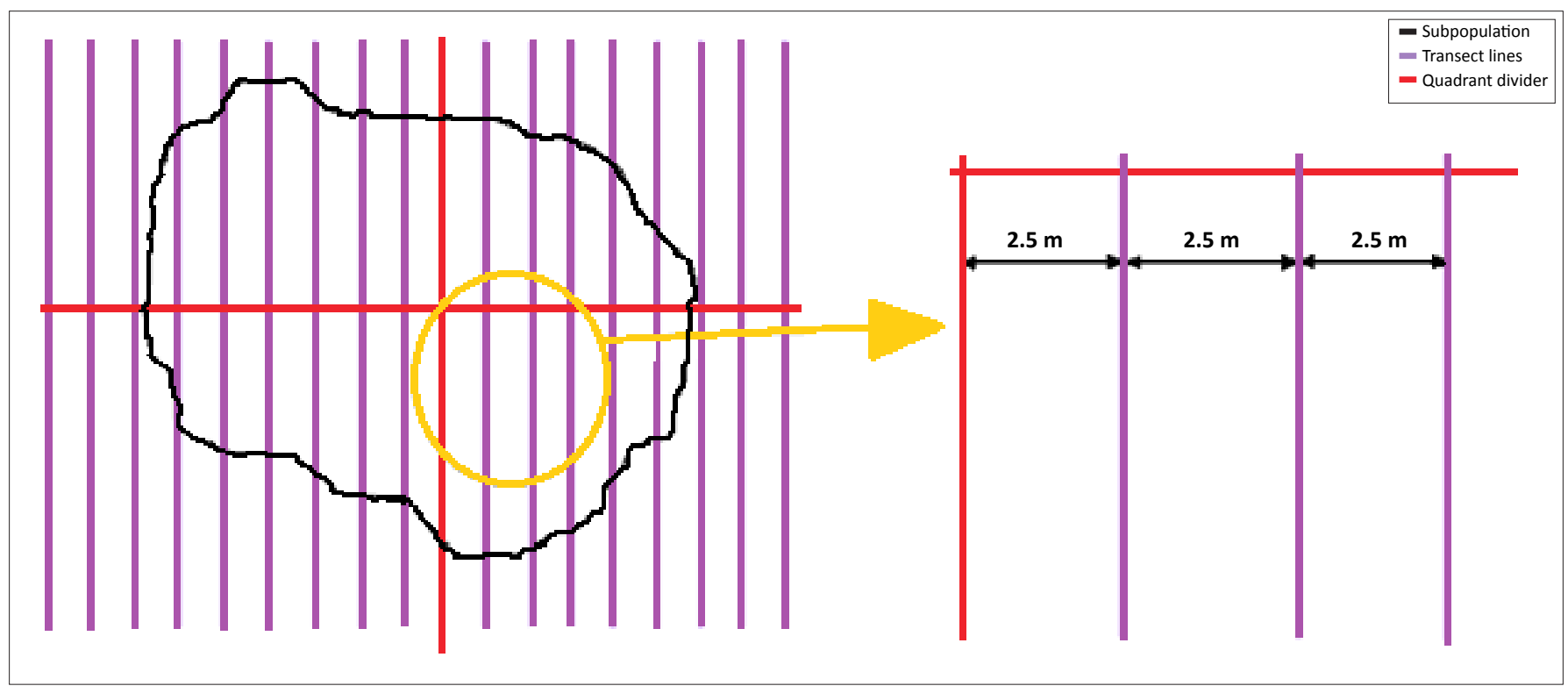

FIGURE 3: Illustration of the transects layout in the different subpopulations of Haworthia koelmaniorum var. mcmurtryi.

\section{Habitat features}

Species composition of associated vegetation, aspect, slope and altitude: The nested quadrate method was used to determine the species composition of the plant community associated with the $H$. koelmaniorum var. momurtryi population. The method, which is explained in Bonham (1989), is normally used to determine the minimum sample area. In this case it was used to determine the species composition of the site of occurrence of H. koelmaniorum var. mcmurtryi. The aspect and altitude of the area of occurrence of the subpopulations were determined according to existing topo-cadastral maps and by using the global positioning system (GPS) in the field. The slope was visually estimated and classified into five broad categories: none $\left(0^{\circ}-3^{\circ}\right)$, gentle $\left(3^{\circ}-8^{\circ}\right)$, moderate $\left(8^{\circ}-16^{\circ}\right)$, steep $\left(16^{\circ}-26^{\circ}\right)$ and very steep $\left(>26^{\circ}\right)$.

Basal grass cover and fire: The basal grass cover in an area of $50 \mathrm{~cm} \times 50 \mathrm{~cm}$ around randomly selected plants was estimated as the percentage of ground covered by the grass-rooted parts. The $50 \mathrm{~cm} \times 50 \mathrm{~cm}$ square was subdivided into $10 \mathrm{~cm}$ $\times 10 \mathrm{~cm}$ squares, giving a total of 25 of these smaller squares (Figure 4). Each small square represented $4 \%$ of the total area. A detailed historical investigation of the occurrence (i.e. the frequency and extent) of fire in the subpopulations situated in the LDNR was completed using the reserve's records. Such investigation was more difficult for the subpopulations outside the reserve because there was no viable source of information. The effect of fire on the randomly selected plants was investigated and the percentage of the plant damaged by fire was estimated subjectively as the proportion of damaged leaves compared to the total number of leaves.

Soil, geology and rock cover: The soil types and geology of the population were identified using the geographical information system data provided by the Mpumalanga Tourism and Parks Agency. The soil forms were confirmed on the ground by digging soil profiles. The rock cover data were collected separately in both the $50 \mathrm{~cm} \times 50 \mathrm{~cm}$ square used for basal grass cover and a $30 \mathrm{~cm} \times 30 \mathrm{~cm}$ square. The same device used for the basal grass cover was used to determine the rock cover and it was expressed as the percentage above ground rock cover.

\section{Data analysis}

Analysis of variance (ANOVA) tests were performed on the data to check for significant differences between the subpopulations in terms of subpopulation structure, basal grass cover, fire damage and percentage rock cover. Where the subpopulations were found to have a significant difference, pairwise multiple comparison (Tukey-Kramer) tests were used to identify which of them differed significantly and to what extent. The tests were performed using the SigmaStat version 2.03 statistical package (SigmaStat 1997).

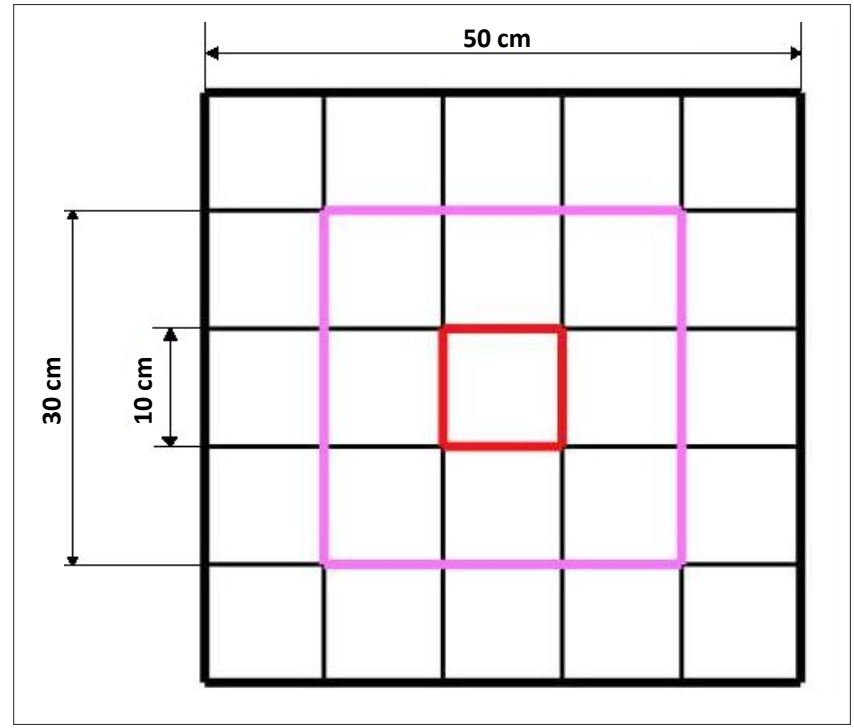

FIGURE 4: Illustration of the device used for determining the rock and basal grass covers within the study area. 


\section{Results}

\section{Population size and structure}

The population consisted of four subpopulations, called A, $\mathrm{B}, \mathrm{C}$, and $\mathrm{D}$ respectively, occurring in an area with a radius of approximately $3 \mathrm{~km}$. Two of the subpopulations (B and C) are protected within the reserve, whilst the other two (A and D) occur outside. The population comprised a total of 1284 plants. The sizes of Subpopulations A, B, C, and D were $368,312,276$ and 328, respectively. The population structure showed that the population comprised of $4 \%$ seedlings, $12 \%$ juveniles and $84 \%$ mature plants (Figure 5). There was no significant difference in the structure of the different subpopulations $\left(\mathrm{F}_{3,8}<1, p>0.05\right)$.

\section{Associated species composition, aspect, slope and altitude}

H. koelmaniorum var. momurtryi was found to be associated with grassland. The most dominant grass in the area was Tristachya biseriata, followed by Themeda triandra, Loudetia simplex, Melinis repens and Diheteropogon amplectens, which was true for all subpopulations. It was found that $H$. koelmaniorum var. momurtryi was generally associated with the northern aspect. The population was associated with high altitudes (between $1380 \mathrm{~m}$ and $1415 \mathrm{~m}$ above sea level) and the slope varied across the different subpopulations. The slope in Subpopulation A was gentle $\left(3^{\circ}-8^{\circ}\right)$, whilst Subpopulation B had steep slope $\left(16^{\circ}-26^{\circ}\right)$, and Subpopulations $C$ and D had a very steep slope $\left(26^{\circ}-45^{\circ}\right)$.

\section{Basal grass cover}

The average basal grass cover was $17 \%$ for the population. The percentage basal grass cover per subpopulation is shown in Figure 6. Pairwise multiple comparison procedures (Tukey test) revealed that only Subpopulation D differed significantly from all the other subpopulations regarding basal grass cover (Table 1). This means that despite apparently similar grass cover throughout the whole population, site-specific grass covers (around individual plants) in Subpopulation D differ significantly from those of the other subpopulations.

\section{Fire}

Existing data from the reserve reveal that the area burns at least once every two to three years, mostly by accidental fires. In addition, one of the subpopulations inside the reserve (Subpopulation B) is partly situated on a firebreak area and is therefore partly burned every year between April and May. As shown in Figure 7, approximately $71 \%$ of all plants in the entire population were affected by fire $(76 \%, 70 \%, 56 \%$ and $83 \%$ for Subpopulations A, B, C and D, respectively). The average percentage fire damage per affected plant was approximately 42\% (Figure 6). A Tukey-Kramer multiple comparisons test revealed that the difference in the percentage fire damage was significant only between Subpopulations A and C and Subpopulations C and D (Table 1).

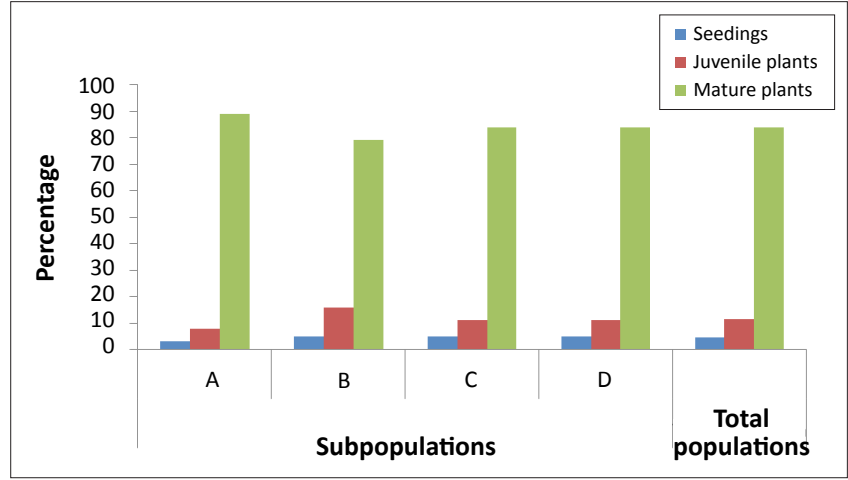

FIGURE 5: Population structure of Haworthia koelmaniorum var. Mcmurtryi across the four subpopulations and the total population indentified within this study.

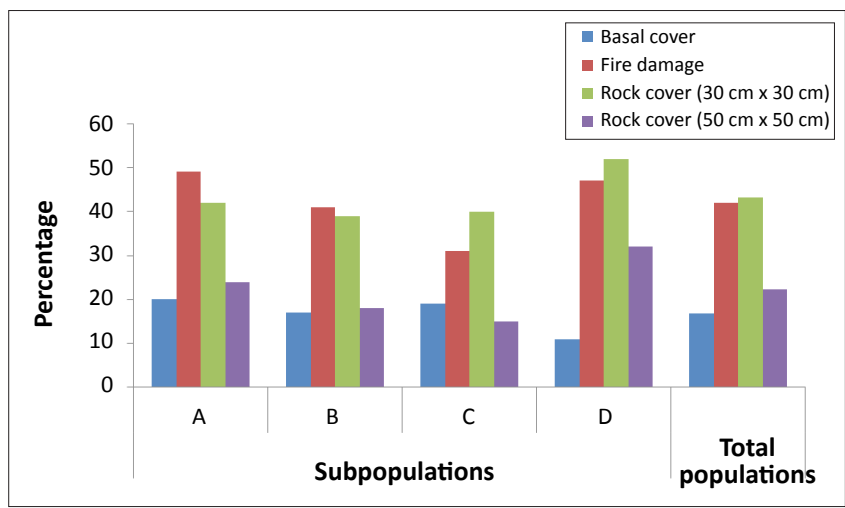

FIGURE 6: Percentage basal grass cover, fire damage and rock cover pe subpopulation and total population of Haworthia koelmaniorum var. Mcmurtryi within the study area.

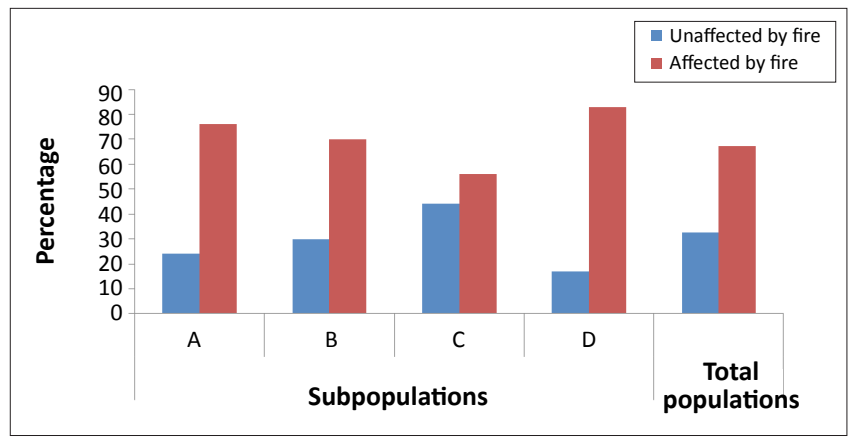

FIGURE 7: Percentage of Haworthia koelmaniorum var. Mcmurtryi affected or unaffected by fire per subpopulation and total population within the study area.

\section{Soil and geology}

H. koelmaniorum var. momurtryi was found only on red rhyolite of the Selons River Formation (Walraven 1978), occurring mainly on hilly rocky outcrops. These results were in accordance with those of Bosch (2004), who describes rhyolite as a felsic volcanic rock with a porphyritic texture. The soil types were the same for all the subpopulations and were positively identified as Glenrosa (Orthic A and Lithocutanic B) and Mispah (Orthic A and Hard rock) soil forms. All the subpopulations were found on both soil types. These are shallow soils with a clayey Orthic A layer. A more detailed account of the geology and pedology associated with this species is provided by Bosch (2004). 


\section{Rock cover and rock size}

There was a significant difference in rock cover between the subpopulations, both in the $30 \mathrm{~cm} \times 30 \mathrm{~cm}$ and the $50 \mathrm{~cm} \times$ $50 \mathrm{~cm}$ squares $\left(\mathrm{F}_{3,318}=6.652, p<0.001\right.$ and $\mathrm{F}_{3,318}=25.787$, $p<0.001$, respectively). The percentage rock cover per subpopulation is shown in Figure 6. In the $30 \mathrm{~cm} \times 30 \mathrm{~cm}$ square, only the differences between Subpopulations $A$ and $D, B$ and D, and C and D were significant (Table 1). In the $50 \mathrm{~cm}$ $\times 50 \mathrm{~cm}$ square, only the difference between Subpopulations $B$ and $C$ was not significant (Table 1). These results are probably because of the fact that the rock size varied greatly between the different subpopulations, with Subpopulation A having predominantly small stones $(20 \mathrm{~mm}-75 \mathrm{~mm}$ in diameter), Subpopulations B and C having predominantly stones (76 $\mathrm{mm}-250 \mathrm{~mm}$ in diameter), and Subpopulation $\mathrm{D}$ having mostly rocks (> $250 \mathrm{~mm}$ in diameter). This result was expected because of the fact that the plants seemed to be selecting specific conditions that changed drastically over a very short distance around them.

\section{Discussion}

For a plant with a highly specialised habitat such as $H$. koelmaniorum var. momurtryi, the population size of 1284 seems to be viable as it surpasses considerably the effective population size of 500 individuals classically proposed by Franklin and Soule (1980). However, the viability of the population has not been verified via pollination studies and the fact that none of the subpopulations is more than 500 individuals in size is of concern as this constitutes a major threat to the viability of the population if the subpopulations are isolated in terms of pollinators. The population size of $H$. koelmaniorum var. mcmurtryi thus means that it can survive, provided its habitat is available and, more importantly, provided the subpopulations are connected by pollination vectors. It should be noted that there are factors that can further threaten the survival of this population even if the subpopulations are connected. These include the occurrence of large disturbance events (prolonged droughts and disruption of the reproductive system by fire) and human impacts (habitat loss and excessive plant collection). These factors, especially human-related factors, need to be monitored carefully.

The population structure provides a snapshot of the current demographic situation, from which some insights can be drawn (Baskin \& Baskin 1986; Widyatmoko \& Norton
1997). In this study, the population structure suggests at least some recruitment by sexual reproduction, although the proportion of seedlings is very low. Such a low level of recruitment suggests that this population is under stress and faces a high risk of extinction if the plants do not have a long lifespan. Long lifespans may buffer populations against the rapid extinction potentially caused by a series of 'bad years' for reproduction or germination, if extant individuals survive (Watson, Westoby \& Holm 1997). Annual seedling recruitment becomes less important in this context, as a result of the long period that each plant has to replace itself (Pierson \& Turner 1998). The lifespan of H. koelmaniorum var. momurtryi should be investigated in order to conclude whether this level of recruitment is acceptable or not.

The dominant grasses of the habitat preferred by $H$. koelmaniorum var. momurtryi usually form dense tufts with shady spots at the base, thus providing sufficient shade and stable environmental conditions necessary for the survival of this plant in its highly unpredictable and stressful habitat (high wind speed, high water runoff speed and exposure to direct sunlight). Most of these grasses are also unpalatable (except for T. triandra that is considered highly palatable on the Highveld) and most of the time they are not grazed, providing a secure space against trampling. These densely tufted dominant grasses in the preferred habitat of $H$. koelmaniorum var. momurtryi may also play an important role in breaking the speed of violent surface water flow associated with heavy downpours of thunderstorms during the summer months when germination occurs. These grasses may therefore become critical for seedling establishment as heavy downpours have been cited as one of the factors accounting for the low rate of seedling establishment (Bosch 2004). It is believed that these densely tufted grasses provide refuges for seed germination and seedling establishment shielded from being washed away by the runoff water.

The significant difference in basal grass cover between Subpopulation D and all the other subpopulations may be explained by the fact that Subpopulation D is found on a communal land that is used as grazing for livestock. The significantly lower basal cover in this subpopulation suggests that it is more exposed to disturbances such direct exposure to sunlight (causing higher fluctuations in temperature), higher wind velocity (that may prevent effective pollination) and higher runoff water velocity (that may prevent seedling establishment) than the other subpopulations. The effects

TABLE 1: Results of the Tukey-Kramer multiple comparisons test for the percentage basal grass cover, percentage fire damage to individual plants and percentage rock cover within the study area.

\begin{tabular}{|c|c|c|c|c|c|}
\hline \multirow[t]{2}{*}{ Variables } & \multicolumn{4}{|c|}{ Subpopulations } & \multirow[t]{2}{*}{$p$-value } \\
\hline & A & B & C & D & \\
\hline Basal grass cover (\%) & $20.15^{\mathrm{a}}$ & $16.89^{\mathrm{a}}$ & $18.62^{\mathrm{a}}$ & $11.46^{b}$ & $p<0.001$ \\
\hline Fire damage to individuals (\%) & $48.91^{\mathrm{a}}$ & $40.76^{\mathrm{a}, \mathrm{b}}$ & $30.51^{\mathrm{b}}$ & $47.37^{\mathrm{a}}$ & $p<0.01$ \\
\hline Rock cover (\%) $50 \mathrm{~cm} \times 50 \mathrm{~cm}$ & $23.67^{\mathrm{a}}$ & $18.03^{b}$ & $15.11^{\mathrm{b}}$ & $32.19^{c}$ & $p<0.001$ \\
\hline Rock cover (\%) $30 \mathrm{~cm} \times 30 \mathrm{~cm}$ & $42.45^{\mathrm{a}}$ & $39.06^{a}$ & $40.46^{a}$ & $52.48^{b}$ & $p<0.001$ \\
\hline
\end{tabular}

$a, b, c$, These superscripts denote significant differences. Values with the same superscript do not differ significantly. 
of these disturbances on $H$. koelmaniorum var. mcmurtryi are as yet unknown and such exposure could mean a higher risk of extinction of this subpopulation. More research is needed to determine the effects of these disturbances on $H$. koelmaniorum var. momurtryi.

It has been hypothesised that succulents are either intolerant of fire and survive only in refuges such as rocky and sandy areas which contain very little fuel, or they are tolerant of fire (Thomas \& Goodson 1992). The percentage rock cover around every individual plant, and the fires that occurred in 2004 and 2006, suggest that H. koelmaniorum var. momurtryi survives best in fire refuges. However, this does not mean that $H$. koelmaniorum var. momurtryi is not fire tolerant. It has been shown that the seeds of species adapted to fire, such as those of H. koelmaniorum var. momurtryi, usually have hard seed coats (Baskin \& Baskin 1998). Such hard coats can be broken by high temperatures produced during combustion, facilitating the entry of water and the emergence of the embryo (Baskin, Baskin \& Xaojie 2000).

The absence of post-fire mortality cannot be explained completely by the refuge hypothesis. In fact, the growth habit of this plant suggests that it is adapted to survive fire. This includes the protection of meristems, both by numerous leaf bases and by their occurrence at or below ground level. Thus, even though $H$. koelmaniorum var. momurtryi uses rock cover as refuge in some cases, it is most likely that the plant is fire tolerant and uses its underground meristem as the mechanism whereby it tolerates fire. More research is needed in this field before a reliable conclusion can be reached, especially in terms of the optimum fire frequency and intensity required by this plant.

\section{Conclusion}

In successfully describing one of the two known populations of H. koelmaniorum var. Mcmurtryi, this study has provided valuable baseline information on this species. Based on the total number of the population, it appears as though this species can survive as it surpasses the effective population size of 500 individuals generally accepted for such rare species. However, the fact that none of the subpopulations is bigger than 500 individuals in size means that such survival is possible only if the different subpopulations are connected by pollination vectors. A further condition to the survival of this species is the preservation of its habitat. This study has successfully described a method that could help in future to categorise the plants in age groups and thus to determine the structure of different (sub)populations. The population structure shows some form of recruitment, although this appears to be very low. More research on the lifespan of this plant is required in order to conclude whether such a low recruitment rate can be considered acceptable for this plant species. The study has also described the habitat features of this species and it was found that H. koelmaniorum var. momurtryi selects very stable conditions where environmental variations and disturbances (exposure to direct sunlight, wind speed, and fire) are minimal. It is suggested that this species is adapted to fire even though it uses refuges to minimise its effects.

For comparison purposes, future autecological studies on this plant are encouraged to use the same methods and age groups described within this study. More detailed investigations should be conducted to identify, map and describe all new populations. It is recommended that more detailed research be undertaken to determine the optimum fire frequency and intensity for these plants, especially for the subpopulation situated on a fire break. More research should also be undertaken to identify the possible pollinators and seed viability of this plant. An assessment of threats and a population viability analysis should be conducted on the known populations of the plant species so that necessary conservation measures can be recommended and implemented.

\section{Acknowledgements}

This project was made possible by the financial assistance of the Tshwane University of Technology (TUT), Shikar Safaris and the Department of Nature Conservation at TUT.

\section{References}

Baskin, J.M. \& Baskin, C., 1986, 'Some considerations in evaluating and monitoring populations of rare plants in successional environments', Natural Areas Journal 6, 26-30.

Baskin, J.M. \& Baskin, C., 1998, Seeds, ecology, biogeography and evolution of dormancy and germination, Academic Press, San Diego.

Baskin, J.M., Baskin, C. \& Xaojie, L., 2000, 'Taxonomy, anatomy and evolution of physical dormancy in seeds', Plant Species Biology 15, 139-152. doi:10.1046/ j.1442-1984.2000.00034.x

Baumgärtner, S., Becker, C., Faber, M. \& Manstetten, R., 2006, 'Relative and absolute scarcity of nature. Assessing the roles of economics and ecology for biodiversity conservation', Ecological Economics 59, 487-498. doi:10.1016/j. ecolecon.2005.11.012

Bayer, B., 1999, Haworthia revisited, a revision of the genus, Umdaus Press, Hatfield.

Bonham, C.D., 1989, Measurements for terrestrial vegetation, John Wiley \& Sons Ltd, Chichester.

Bosch, P.J.A., 2004, 'The geological, pedological and climatic influence on variety generation in Haworthia koelmaniorum var. koelmaniorum and $\mathrm{H}$. koelmaniorum var. mcmurtryi', Aloe 41, 56-60.

Dobson, A.P., 2000, Conservation and biodiversity, Scientific American Library, New York.

Ellstrand, N.C. \& Elam, D.R., 1993, 'Population genetic consequences of small population size: Implications for plant conservation', Annual Review of Ecology and Systematics 24, 217-242. doi:10.1146/annurev.es.24.110193.001245

Farnsworth, E.J., Klionsky, S., Brumback, W.E. \& Havens, K., 2006, 'A set of simple decision matrices for prioritizing collection of rare plant species for ex situ conservation', Biological Conservation 128, 1-12. doi:10.1016/j. ex situ conservation

Franklin, I.R. \& Soulé, M.E., 1980, 'Evolutionary changes in small populations', in M.E Soulé \& B.A. Wilcox (eds.), Conservation biology, an evolutionary-ecological perspective, Sinauer Associates, Inc., Sunderland.

Hilton-Taylor, C., 1996, 'Red data list of southern African Plants', Strelitzia 4, National Botanical Institute, Pretoria.

Holsinger, K.E., 2000, 'Reproductive systems and evolution in vascular plants', Proceedings of the National Academy of Sciences USA 97, 7037-7042.

Kruger, A.C., 2004, Climate of South Africa. Climate regions. WS45, South African Weather Service, Pretoria.

Lötter, M., Biko'o, A. \& Victor, J.E., 2009, 'Haworthia koelmaniorum var. Mcmurtryi', in D. Raimondo, L. von Staden, W. Foden, J.E. Victor, N.A. Helme, R.C. Turner et al. (eds.), Red list of southern African Plants 2009, Strelitzia 25, South African National Biodiversity Institute, Pretoria. 
Menges, E.S. \& Dolan, R.W., 1998, 'Demographic viability of Silene regia in Midwestern prairies and relationships with fire management, genetics, geography, population prairies and relationships with fire management,
size, and isolation', Journal of Ecology $86,63-78$.

Mpumalanga Government, 1998, Mpumalanga Nature Conservation Act Mpumalanga Government, Nelspruit.

Mucina, L. \& Rutherford, M.C. (eds.), 2006, 'The vegetation of South Africa, Lesotho and Swaziland', Strelitzia 19, South African National Biodiversity Institute, Pretoria.

Pfab, M.F. \& Witkowski, E.T.F., 1999, 'Contrasting effects of herbivory on plan size and reproductive performance in two populations of the critically endangered species, Euphorbia clivicola R.A. Dyer', Plant Ecology 145, 317-325. doi:10.1023/A:1009869011237

Pierson, E.A. \& Turner, R.M., 1998, 'An 85-year study of saguaro (Carnegiea gigantean demography', Ecology 79, 2676-2693. doi:10.1890/0012-9658(1998)079[2676:AY demography', Ecology 79, 2676-2693
SOSC]2.0.CO;2, doi:10.2307/176509

Pimm, S.L. \& Raven, P.H., 2000, 'Extinction by numbers', Nature 403, 843-845 doi:10.1038/35002708, PMid:10706267

Primack, R.B., 1993, Essentials of conservation biology, Sinauer Associates, Inc. Sunderland.

Secretariat of the Convention on Biological Diversity, 2005, Handbook of the convention on biological diversity including its Cartagena protocol on biosafety 3rd edn., Secretariat of the Convention on Biological Diversity, Montreal.
SigmaStat version 2.03, 1997, computer software, SPSS Inc., Chicago.

Thomas, P.A. \& Goodson, P., 1992, 'Conservation of succulents in desert grasslands managed by fire', Biological Conservation 60, 91-100. doi:10.1016/00063207(92)91159-P

United Nations, 1992, 'Convention on biological diversity', proceedings of the United Nations conference on environment and development, Rio de Janeiro, Brazil, June 03-14, 2002.

Van Dyke, F., 2003, Conservation biology: Foundations, concepts, applications, McGraw-Hill Companies, New York.

Walraven, F., 1978, 1:250 000 scale geological series, 2428 Pretoria, Council for Geoscience (Geological Survey of South Africa), Pretoria.

Watson, I.W.M., Westoby, A. \& Holm, M.C.R., 1997, 'Continuous and episodic components of demographic change in arid zone shrubs: Models of two Eremophila species from Western Australia compared with published data on other species', Journal of Ecology 85, 833-846. doi:10.2307/2960605

Widyatmoko, D. \& Norton, D.A., 1997, 'Conservation of the threatened shrub Hebe cupressoides (Scrophulariaceae), Eastern South Island, New Zealand', Biological Conservation 82, 193-201. doi:10.1016/S0006-3207(97)00016-5 